\title{
Estratégias de mercado no agronegócio paranaense: soja convencional vs. transgênica
}

\author{
José Veríssimo Foggiatto Silveira, ${ }^{\mathrm{a}, *}$, Luis Maurício Resende ${ }^{\mathrm{b}}$ \\ a,*foggiattojv@ @otmail.com, UTFPR-PG, Brasil \\ blmresende@utfpr.edu.br, UTFPR-PG, Brasil
}

\begin{abstract}
Resumo
0 objetivo deste trabalho foi determinar os fatores comparativos de custos de produção entre a soja convencional e a transgênica para subsidiar estratégias de decisão de atores do agronegócio, utilizando-se como região de análise o Estado do Paraná. Verificou-se que os argumentos sobre o menor custo com a introdução da soja transgênica não são corretos. Constatou-se, também, por este estudo que existe uma praticidade na tecnologia da soja transgênica, mas também existem argumentos e dados que podem questionar o uso dessa tecnologia, tanto no aspecto econômico quanto técnico. Mesmo com a redução significativa de custo pelo menor uso de herbicidas na soja transgênica, esse fato é minimizado pelo maior preço atual cobrado pela semente da variedade de soja transgênica, pela taxa tecnológica cobrada pelo uso do gene e pela menor produtividade apresentada pelas variedades de soja transgênicas lançadas no mercado em relação às variedades de soja convencionais.
\end{abstract}

Palavras-chave

Soja transgênica. Estratégias de mercado. Custos comparativos de produção.

\section{Introdução e objetivos}

0 crescimento da população, principalmente nos centros urbanos, gera uma necessidade crescente por alimentos, que são supridos por produtos básicos provenientes da agricultura. Porém, além do aspecto quantitativo, surge também o qualitativo, em que consumidores exigentes passam a valorizar características diferenciadas de produtos, com preocupações extras referentes à preservação ambiental e qualidade de vida. Esses clientes, com características diferenciadas, passam a formar um mercado segmentado em que a estratégia de atuação deve estar sustentada primeiramente nesses consumidores e não no produto em si. Portanto, aqueles que ofertarem produtos diferenciados que atendam a esse mercado terão maiores chances na acirrada concorrência globalizada.

0 agronegócio brasileiro inserido no mercado global deve estar em sintonia com todos os fatores que interferem nos seus resultados. Atentar para possibilidades de mercado composto por consumidores especiais permite direcionar um determinado produto para essa demanda. Para mercados amplos como a produção de commodities, pode-se utilizar também de estratégia de diversificação de produtos orientados para nichos de mercado e não somente aos de custo baixo com altos volumes.

Apartir da exigência de uma fatia deconsumidores, principalmente europeus, por produtos não geneticamente modificados (não OGMs), os gestores da cadeia produtiva da soja passaram a ter mais uma preocupação: a de separar a soja convencional da soja transgênica ou geneticamente modificada. Esse antagonismo aos OGMs se desencadeou a partir de problemas ocorridos na Europa, e mais recentemente na Ásia, ocasionados pelas doenças denominadas de "vaca louca" (Bovine Spongiform Encephalopathy - BSE) e a gripe aviária, respectivamente. Esses acontecimentos acarretaram questionamentos em relação à segurança dos alimentos, fortalecendo uma posição contrária aos OGMs.

A primeira soja transgênica lançada comercialmente, obtida com a transformação genética de plantas através da engenharia genética, difere da soja convencional por possuir um gene que expressa resistência ao herbicida de ação total denominado de glifosato. A introdução desse gene facilitou o controle das ervas daninhas, e seu uso se generalizou em algumas regiões, quando, ao mesmo tempo, surgiram reações com críticas à segurança dessa nova tecnologia. 
No Brasil, o estado que efetivamente iniciou o plantio da soja transgênica em grande escala foi o Rio Grande do Sul, com a introdução de variedades clandestinas da Argentina, país onde o plantio da soja transgênica já é liberado há muito mais tempo. A principal alegação do uso da soja transgênica, pelos produtores do Rio Grande do Sul, foi a diminuição de custo pelo menor número de pulverizações e produtos para combater ervas daninhas.

Por outro lado, o governo do Estado do Paraná sustenta uma posição contrária à introdução da soja transgênica, esforçando-se pela não utilização dessa tecnologia pelo setor produtivo, tentando preservar o seu mercado de soja convencional vislumbrando um mercado cativo futuro. Para isso, o governo do Paraná aprovou uma Lei estadual em 2003 para prevenir a entrada, comercialização e produção de soja transgênica. Mesmo com a suspensão dessa Lei pelo Supremo Tribunal Federal, o governo desse estado permaneceu com uma postura contrária à introdução da soja transgênica com argumentos de transformar esse estado em "área livre de transgênicos" atendendo a um mercado externo que, por hipótese, pagará um prêmio adicional.

Afirmações são feitas em relação à redução de custos com a introdução da soja transgênica e também de vantagens competitivas com a permanência do cultivo da soja convencional, mas as evidências até aqui demonstradas são praticamente por hipóteses. Sabe-se que existem muitas variáveis regionais e de cunho técnico que interferem nos resultados e que não estão sendo levadas em conta quando se defende ou se critica a tecnologia "soja transgênica". Essa polêmica em torno da soja transgênica persiste e mostra uma tendência de conflitos entre os atores do agronegócio do Estado do Paraná: o governo desse estado, a multinacional detentora da patente do gene presente na primeira soja transgênica que expressa a resistência ao herbicida glifosato, produtores e pesquisadores.

0 foco deste trabalho, então, foi determinar os fatores comparativos e compor os custos de produção entre a soja convencional e a transgênica para subsidiar estratégias de decisão de atores do agronegócio paranaense. Consequentemente, em função dos resultados de custos obtidos obteve-se o sobrepreço estimado da soja convencional para justificar sua certificação e manutenção da sua produção. 0 estudo se restringiu ao caso da inserção da tecnologia transgênica no Estado do Paraná pormenorizando duas cooperativas localizadas nas cidades de Castro e Carambeí, na região dos Campos Gerais, área Centro Oriental desse estado. Juntas, essas duas cooperativas agropecuárias possuem 937 agricultores com 150.000 ha, representando uma produção de 900.000 toneladas de grãos, sendo $60 \%$ de milho e $40 \%$ de soja. A maior parte das suas produções de soja destina-se ao mercado externo, principalmente para a Europa.

Portanto, a questão é: como decidir por uma tecnologia, quando ocorrem incertezas relacionadas ao seu custo comparativo? A adesão dos produtores agrícolas por uma determinada tecnologia é influenciada diretamente pelo custo e pela praticidade de uso. Por outro lado, esses dois fatores não garantem a sua utilização, pois outros fatores produtivos também interferem na decisão de uso, como preços e produtividade relativa.

\section{Estratégia de segmentação para mercados competitivos}

0 mercado agrícola como agente exportador e de aquecimento da economia brasileira deve orientar-se para o ambiente externo com estudos da concorrência e ações que respondam a mercados diferenciados. As estratégias intuitivas tornam-se injustificadas pelos riscos atuais impostos pela concorrência acirrada do mercado. Quando se depara com o cenário dinâmico globalizado, uma gestão estratégica passa por algumas fases, como planejamento financeiro, previsão a longo prazo e planejamento orientado para o mercado externo.

As empresas do agronegócio não escapam dessa visão. 0 fato de estar atento para necessidades específicas condiciona o setor produtivo a estabelecer variáveis geográficas, demográficas ou psicográficas dos consumidores, possibilitando conhecer de forma concreta suas necessidades, a dimensão desse mercado e a criação de produtos diferenciados. A exigência por produtos diferenciados, vinda de clientes especiais com preocupações sobre qualidade e preservação ambiental cada vez mais será observada. (KOTLER, 1989).

Nesse sentido, Porter (1986) descreve que, de acordo com o mercado a ser atendido, amplo ou restrito, pode-se formar estratégias de liderança em custo e diferenciação de produto. Em mercados globalizados, a utilização de estratégias de custos como único fator não é suficiente para sustentar uma vantagem competitiva. Por isso, a adoção de uma estratégia diferenciada permite a adaptação às mudanças dinâmicas impostas pelo mercado, utilizando dessa forma toda a competência das empresas para um determinado produto.

A concentração das exportações de matériaprima do Brasil ainda se traduz em práticas inapropriadas que devem ser substituídas por estratégias que busquem melhores perspectivas de comércio, posicionando produtos diferenciados 
que sejam valorizados pelo mercado consumidor (CARVALHO, 2002). Apesar de o volume de exportação das commodities agrícolas do Brasil ser expressivo, esse fato nem sempre reverte numa vantagem considerável, pois estão sujeitas a variações de preços no mercado pelo valor dos estoques mundiais. Mesmo o Brasil sendo um dos maiores produtores e exportadores de soja, ainda é tomador de preços, pois as variações no mercado internacional, motivadas pelos estoques globais, repercutem integralmente no mercado interno do Brasil (MARGARIDO et al., 2002).

A soja brasileira, portanto, pode ser trabalhada no cenário mundial com argumentos de marketing partindo-se de características diferenciadas de qualidade. Para tirar proveito comercial desses fatos, são necessárias identificações, quantificações, padronizações e certificações de conformidade desses produtos.

A Comissão Europeia (2003), ao analisar os produtos segmentados, afirma que o mercado de produtos obtidos através de sistemas de preservação de identidade tem expectativa de crescimento tanto em número como em nichos de mercado, com ou sem a presença de organismos geneticamente modificados (OGMs). Nos EUA, é estimada uma participação de 10\% na produção agrícola com sistemas de identidade preservada e espera-se um incremento de $30 \%$ em dez anos. Uma pesquisa de mercado sobre potenciais importadores, volume, custos inerentes à segmentação, estimativas de preços e logística de distribuição (portos e rodovias) deve ser realizada antes da decisão pela diversificação. Ofertar um produto diferenciado pode exercer influências positivas no mercado consumidor. Estabelecido o produto diferenciado e definido o consumidor, deve-se atentar para a efetivação de contratos de compra e venda. Essa formalização diminui riscos característicos de mercados ainda inconsistentes (MARQUES; AGUIAR, 1993).

Nessa perspectiva, algumas cooperativas do Estado do Paraná, visualizando um mercado específico e evitando possíveis barreiras às suas exportações, certificam a sua produção de soja convencional, evitando contaminação por soja transgênica. Com isso, tenta-se a valorização do produto, orientando-o para mercados específicos (SILVEIRA et al., 2003).

Com o mesmo propósito, mas de uma forma extremada, o governo do Estado do Paraná segue uma linha de precaução, tentando preservar 0 seu mercado de soja convencional, alegando a possibilidade de esta ser contaminada pela soja transgênica, o que dificultaria a exportação para mercados exigentes. Além disso, alega também o aumento de custos com a introdução da soja transgênica devido à necessidade de segregação e certificação para evitar contaminações da soja convencional.

De fato, para a distinção de produtos agroalimentares que atendam a mercados segmentados, é necessária a utilização de ferramentas para a preservação da identidade, garantindo dessa forma as suas qualidades. A partir da introdução dos produtos geneticamente modificados, são necessários instrumentos de coordenação para as devidas segregações (GIORDANO, 1999; CHADDAD et al., 2002). Alguns produtos de soja já são incluídos em sistemas de preservação da identidade, objetivando valorizá-los atendendo a mercados específicos: soja orgânica, variedades para produção de tofu e, mais recentemente, a produção de soja convencional para diferenciar-se da transgênica.

Por outro lado, para garantir o mercado, uma empresa multinacional detentora da patente do gene que expressa uma inovação revolucionária na produção da soja tenta disseminá-la de uma forma generalizada no Brasil, afirmando que essa tecnologia fornecerá comodidade e ganhos econômicos para o produtor.

Esse artigo não teve a finalidade de aprofundar-se nessa polêmica com a soja transgênica, o que envolve controvérsias éticas, sanitárias, alimentares, ambientais e econômicas. Para um melhor entendimento dessa polêmica, Silveira (2005) apresenta o resultado de uma pesquisa utilizando-se de entrevistas com sete atores do agronegócio para mostrar as argumentações sobre a soja transgênica. Esses argumentos foram agrupados em três aspectos: tecnologia, mercado e meio ambiente. Em relação à tecnologia, os argumentos positivos foram: praticidade de uso, custo mais baixo e uma ferramenta a mais na agricultura. Quanto aos argumentos negativos em relação à soja transgênica, destaca-se o maior custo das sementes transgênicas e dúvidas sobre sua produtividade.

Essa polêmica em torno dos transgênicos persiste por um período considerável e mostra uma tendência crescente de conflitos entre os atores desse agronegócio: o governo do Estado do Paraná, a multinacional detentora do primeiro evento de transgenia da soja introduzido no Paraná, produtores e pesquisadores. Como o fenômeno soja transgênica é recente, os dados e informações sobre o assunto são escassos. Dessa forma, é oportuno o levantamento de dados relacionados aos custos de produção comparativos entre as duas tecnologias: soja convencional versus transgênica como forma de contribuição para validar ou não argumentos sobre essas tecnologias. 


\section{Custos da soja transgênica}

Um argumento comum no âmbito dos atores do agronegócio é em relação à questão econômica com a introdução da soja transgênica. Nesse sentido, Pelaez (2004) considera ilusória a redução no custo de produção da soja transgênica já que o USDA, o departamento de agricultura americano, constatou em suas pesquisas um aumento de $30 \%$ nos custos com o uso dessa tecnologia a partir do terceiro ano. Além disso, se forem considerados outros fatores para composição dos custos de produção como pagamentos de royalties, custo de segregação, rastreabilidade e produtividade comparativa, poderão surgir resultados que permitirão identificar se a soja transgênica é ou não competitiva em termos econômicos.

Em relação ainda à redução de custos com a utilização da soja transgênica, Morais (2004) relata um deferimento de 2003 de um pedido da multinacional criadora da soja transgênica, nos seguintes termos:

Em síntese, a lide transcende os interesses das partes, pois trata de questões que dizem respeito ao desenvolvimento de técnicas agrícolas para o desenvolvimento sustentável do País, a competitividade do Brasil no mercado internacional de commodities, o avanço na área de pesquisa científica para redução dos custos da produção agrícola com a diminuição de agrotóxicos e o direito do consumidor à informação.

Pode-se constatar a afirmação categórica sobre redução de custos como o uso da tecnologia "soja transgênica”, para tornar o Brasil mais competitivo no mercado internacional de commodities.

Trabalhos mais aprofundados sobre a redução de custo com o uso da soja transgênica ainda são escassos no Brasil. Porém percebe-se que, dentre os argumentos favoráveis à introdução da soja transgênica no Brasil, o fator custo é o mais enfatizado; já, entre os argumentos negativos, é mencionada a sua baixa produtividade. Portanto, tornam-se oportunos maiores esclarecimentos sobre esses argumentos.

A Comissão Europeia (2003), analisando a relação de custo entre a soja transgênica e a soja convencional, informa que, devido à taxa tecnológica agregada na semente da soja transgênica, ela fica mais cara que a semente da convencional. Para a soja transgênica, essa comissão relata um custo de $57 € /$ ha vs. $42 € /$ ha para a convencional. A diferença de $15 € /$ ha corresponde à taxa tecnológica. No atual estágio existem elementos de equilíbrio que podem ser analisados na comparação entre os custos da soja transgênica e a convencional: um é o maior preço da semente da soja transgênica e o outro é a maior produtividade da soja convencional. $\mathrm{Na}$ Tabela 1, resume-se o trabalho apresentado pela Comissão Europeia (2003) no qual se observa uma comparação de retorno para soja transgênica e convencional. Essa Comissão afirma que as diferenças nos custos e nos rendimentos entre essas duas tecnologias fornecem diferenças não significativas sobre a terra e trabalho. Embora o custo total (excluindo terra e trabalho) tenha sido maior na soja não transgênica, esse maior custo foi compensado pela sua maior produtividade $\left(\mathrm{kg} \mathrm{ha}^{-1}\right)$. Afirma ainda que, em trabalhos realizados na Universidade de Illinois - EUA, os custos variáveis da soja não transgênica são de 6 a 8\% maiores que a soja transgênica. Em relação aos preços, foram observadas diferenças somente a partir de 1999, sendo poucos os relatórios de revisões de mercado sobre essas diferenças.

Em relação à produtividade, na maioria dos ensaios realizados nos EUA, a soja transgênica mostrou ser em média 5,3\% menos produtiva que a soja convencional. Através da Tabela 2, constatam-se as diferenças de produtividade entre a soja transgênica e a convencional em diversos estados dos EUA.

Uma das explicações para a baixa performance das variedades transgênicas mostradas na Tabela 2 é que foram comparadas com as variedades convencionais de melhor qualidade. As empresas de sementes, ao longo do tempo, tentarão passar essa maior produtividade das variedades convencionais para as transgênicas.

Ainda em relação à produtividade, Bianchi (2005) apresenta, conforme Tabela 3, as diferenças ocorridas entre variedades padrões de soja convencional e transgênica plantadas no Rio Grande do Sul. A justificativa para essas menores produtividades da

Tabela 1. Comparação de retorno entre a soja transgênica e a convencional.

\begin{tabular}{lcccc}
\multicolumn{1}{c}{ Cultura } & $\begin{array}{c}\text { Produtividade } \\
\left(\mathrm{kg} \cdot \mathrm{ha}^{-1}\right)\end{array}$ & $\begin{array}{c}\text { Custo de semente } \\
(\boldsymbol{\epsilon} / \mathrm{ha})\end{array}$ & $\begin{array}{c}\text { Custo total (excluindo } \\
\text { terra e trabalho) }(\boldsymbol{\epsilon} / \mathrm{ha})\end{array}$ & $\begin{array}{c}\text { Retorno sobre a terra e } \\
\text { trabalho }(\boldsymbol{\epsilon} / \mathrm{ha})\end{array}$ \\
\hline Soja transgênica & 3.295 & 57 & 254 & 320 \\
Soja convencional & 3.430 & 42 & 274 & 322 \\
\hline
\end{tabular}

Fonte: Comissão Europeia (2003) 
Tabela 2. Diferenças de produtividade entre a soja convencional e a transgênica.

\begin{tabular}{|c|c|c|c|}
\hline \multirow{2}{*}{ Estados } & \multicolumn{2}{|c|}{ Produtividade $\left(\mathrm{kg} \cdot \mathrm{ha}^{-1}\right)$} & \multirow{2}{*}{$\begin{array}{c}\text { Diferença } \\
\text { entre as } \\
\text { tecnologias } \\
(\%)\end{array}$} \\
\hline & Convencional & Transgênica & \\
\hline 1llinois & 3.900 & 4.040 & $+3,5$ \\
\hline lowa & 4.100 & 3.830 & $-7,0$ \\
\hline Michigan & 4.440 & 4.300 & $-3,0$ \\
\hline Minnesota & 4.440 & 4.100 & $-8,0$ \\
\hline Nebraska & 3.900 & 3.430 & $-12,0$ \\
\hline Ohio & 4.004 & 3.900 & $-3,0$ \\
\hline $\begin{array}{l}\text { South } \\
\text { Dakota }\end{array}$ & 3.300 & 2.960 & $-10,0$ \\
\hline Wisconsin & 4.770 & 4.640 & $-3,0$ \\
\hline
\end{tabular}

Fonte: Wilkinson (2002).

Tabela 3. Perda em produtividade (\%) das variedades de soja transgênicas em relação às convencionais (média de três safras).

\begin{tabular}{lc}
\hline \multicolumn{1}{c}{ Variedades } & Perdas (\%) \\
\hline CD-201 - convencional & - \\
Melhor variedade transgênica & -12 \\
Pior variedade transgênica & -27 \\
Fundacep - 39 - convencional & - \\
Melhor variedade transgênica & -13 \\
Pior variedade transgênica & -30 \\
\hline Fonte: Bianchi (2005).
\end{tabular}

soja transgênica é embasada no uso de variedades ainda não adaptadas para o Brasil, já que a maioria das variedades plantadas no Rio Grande do Sul veio clandestinamente da Argentina.

Complementando as informações, esse autor afirma que, em levantamento realizado numa área de 2,240 milhões ha plantada com a soja transgênica na safra 2003/2004 no Rio Grande do Sul, a dose média utilizada do glifosato comum foi de 2,7 l.ha ${ }^{-1}$.

Como pode ser observado, o contexto relacionado com a soja transgênica é constituído por um desequilíbrio de argumentos. Dessa forma, visando melhor esclarecer a questão econômica, possibilitando a aceitação ou rejeição de argumentos de atores do agronegócio, foi realizado um levantamento do custo de produção comparativo entre a soja convencional versus transgênica adotando-se os critérios estabelecidos na metodologia.

\section{Metodologia}

Para o delineamento da pesquisa, optou-se, sob o ponto de vista de seus objetivos, por uma pesquisa qualitativa de natureza exploratória e descritiva.

A pesquisa também exigiu uma mescla de evidências qualitativas e quantitativas sem inclusão de métodos estatísticos. Pode-se afirmar que os argumentos sobre o fenômeno contemporâneo - soja transgênica - não estavam claramente definidos.

Como método de coleta de dados utilizou-se de entrevistas individuais com perguntas semiestruturadas. Dessa forma, foram selecionados sete atores para participarem das entrevistas: um gerente da multinacional detentora da patente da soja transgênica que confere resistência ao herbicida denominado de glifosato, introduzida no Estado do Paraná; dois representantes da Secretaria da Agricultura do Estado do Paraná; dois gerentes agrícolas de duas cooperativas da região dos Campos Gerais - Castro e Carambeí - Paraná; um pesquisador de uma Fundação privada de pesquisa em Castro - PR; e um produtor agrícola utilitário da soja transgênica de uma das cooperativas integrantes deste estudo.

No levantamento de dados para elaboração dos custos de produção e evidências quantitativas, levou-se em conta a produtividade individualizada da soja convencional e da soja transgênica, seus respectivos preços de mercado e a logística de segregação.

Para elaboração dos custos comparativos de produção entre soja convencional versus soja transgênica, foi utilizada uma planilha de cálculo adotada pela Fundação de pesquisa que integra 0 estudo, localizada em Castro - PR. A composição da planilha constou de custos variáveis e fixos, próprios da tecnologia empregada na região.

Foram utilizadas variáveis particulares na análise de cada tecnologia, soja convencional e transgênica, separando-se a análise da seguinte forma:

1) Os herbicidas para soja convencional e transgênica com suas respectivas doses;

2) Variáveis preços das respectivas sementes e a taxa tecnológica pelo uso do gene;

3) Variável segregação interna no armazém somente para a soja transgênica;

4) A variável produtividade comparativa entre a soja convencional e a transgênica; e

5) Os preços diferenciados dos grãos da soja convencional versus transgênica.

Neste estudo, considerou-se apenas a segregação interna da soja transgênica. Justifica-se esse procedimento, pois a manipulação de produtos diferenciados em estruturas de armazenamento voltadas para commodities é dificultada, o que requer maiores cuidados na recepção, fluxo e limpeza dos silos. Além disso, exige-se mão de obra específica para acompanhar o fluxo do produto diferenciado de menor escala. Para 
exemplificar melhor esse argumento, cita-se a recepção do milho waxy destinado para a indústria de alimentos para produção de amidos especiais. Ao chegar às cooperativas, recebe um tratamento especial em todo o fluxo de armazenagem, o que representa um maior custo de recepção, secagem e armazenamento. Esse maior custo é compensado em muito pelo sobrepreço que esse produto recebe, que é em média de 48\% em relação ao milho comum. Para este estudo optou-se em agregar o custo de segregação interna da soja transgênica para a soja convencional, pois é essa última que requer diferenciação para obtenção de melhor preço de consumidores específicos.

Os custos da segregação interna da soja transgênica, os preços diferenciados da soja convencional certificada, os preços das sementes e o valor da taxa tecnológica foram fornecidos pelos gerentes das cooperativas estudadas. Em relação à segregação interna dos grãos da soja transgênica e o preço diferenciado dos grãos da soja convencional certificada, foram utilizados os maiores valores dos dados informados. Justifica-se esse procedimento para avaliação do impacto ocasionado pelas melhores oportunidades de mercado.

Para a determinação das doses utilizadas dos herbicidas convencionais, buscou-se a quantidade de produtos mais utilizados em uma das cooperativas estudadas. De posse do volume, dividiu-se pela respectiva área de soja plantada por seus produtores na safra 2005/2006. Esse procedimento foi adotado para os três herbicidas utilizados na soja convencional. A determinação da dose média do glifosato utilizada na soja transgênica foi embasada no rótulo do produto registrado para utilização na soja transgênica. 0 restante dos custos considerou-se igual para as duas tecnologias.

Para verificação dos impactos nos custos inerentes de logística de segregação interna e armazenamento da soja transgênica, inclui-se, em uma das perguntas realizadas aos gerentes das cooperativas, um cenário produtivo futuro constituído de 10\% do volume total da produção de soja recebida com soja transgênica.

Os levantamentos das produtividades comparativas, entre soja convencional e a soja transgênica, foram realizados junto a órgãos de pesquisa que possuíam os dados es disponibilizaram. Essas informações sobre as produtividades relativas entre as variedades transgênicas e as convencionais foram obtidas junto à Embrapa Soja - Londrina - PR que realizou testes em várias localidades, as quais abrangem uma vasta região do Estado do Paraná com climas diferenciados.

\section{Resultados e discussões}

Conforme as informações obtidas com os gerentes agrícolas das duas cooperativas inseridas neste estudo, as sementes de soja transgênicas são fornecidas pelas empresas multiplicadoras licenciadas que cobram royalties. Para o uso da soja transgênica, uma taxa tecnológica é cobrada pela multinacional que possui a patente do gene. Para o uso das sementes de soja transgênica essa multinacional cobra uma taxa tecnológica. No início da cobrança dessa taxa tecnológica a multinacional praticava o valor de $\mathrm{R} \$ 0,88 / \mathrm{kg}$.

Após esse período, forneceu um desconto para as empresas multiplicadoras de sementes credenciadas caindo esse valor para $\mathrm{R} \$ 0,50 / \mathrm{kg}$ de sementes. Atualmente o custo da taxa tecnológica é de $\mathrm{R} \$ 0,30 / \mathrm{kg}$. Para aqueles que produzem grãos de soja transgênica através de sementes próprias ou sem origem, é cobrado, na entrega do produto, um valor de $2 \%$ do preço vigente do saco de $60 \mathrm{~kg}$ da soja grão. Para este estudo, o custo considerado da semente da soja transgênica foi de $R \$ 2,00 / \mathrm{kg}$, e o custo da soja convencional foi de $R \$ 1,40 / \mathrm{kg}$. Assumiu-se, para o presente trabalho, uma demanda de $55 \mathrm{~kg} \cdot \mathrm{ha}^{-1}$ de sementes para o plantio.

Em relação aos preços dos grãos de soja, um dos gerentes agrícolas informou que estão recebendo um valor adicional de 5\% no preço pela soja convencional certificada, num total de $60 \mathrm{mil} \mathrm{t}$. Esse valor representa aproximadamente 30\% da produção total da soja recebida por essa cooperativa. 0 gerente da outra cooperativa informou que estão recebendo um sobrepreço de $1 \%$ com a soja convencional certificada, num total de 40 mil t. Esse valor representa também aproximadamente 30\% da produção total recebida por essa cooperativa. Para realização dos cálculos de custos comparativos de produção se adotará o maior sobrepreço observado, que nesse caso é de $5 \%$.

As informações de produtividade foram obtidas junto à Embrapa Soja (2005). Conforme esse levantamento, as variedades transgênicas de soja foram em média 3,1\% menos produtivas do que as convencionais. Essas variedades foram testadas em 21 locais do Paraná.

$\mathrm{Na}$ Tabela 4, são mostradas as diferenças na produtividade entre a soja convencional e transgênica. Ressalta-se que nesta tabela as variedades transgênicas são comparadas com as suas variedades convencionais recorrentes, isto é, as variedades transgênicas são derivadas das respectivas variedades convencionais comerciais. 
Tabela 4. Produtividade $\left(\mathrm{kg}_{\mathrm{h}} \mathrm{ha}^{-1}\right)$ da soja convencional versus soja transgênica em 21 locais do Paraná - safra 2002/2003.

\begin{tabular}{lcc}
\hline & $\mathrm{kg} \cdot \mathrm{ha}^{-1}$ & Diferença (\%) \\
\hline Embrapa 58 - convencional & 3246 & \\
BRS 242 RR & 3202 & $-1,35$ \\
Embrapa 48 - convencional & 3400 & \\
BRS 243 RR & 3325 & $-2,2$ \\
Embrapa 59 - convencional & 3276 & \\
BRS 244 RR & 3214 & $-1,9$ \\
BRS 133 - convencional & 3457 & \\
BRS 245 RR & 3355 & $-2,9$ \\
BRS 246 RR & 3282 & $-5,0$ \\
BRS 134 - convencional & 3246 & \\
BRS 247 RR & 3077 & $-5,2$ \\
& Média geral & $-3,1$ \\
\hline
\end{tabular}

Fonte: Embrapa Soja (2005).

Constata-se que a perda média de produtividade da soja transgênica em relação à convencional informada pela Embrapa Soja é menor que aquelas observadas por alguns autores: 5,3 e 12\% (WILKINSON, 2002 e BIANCHI, 2005).

0 valor diferenciado de mercado dos grãos provenientes das tecnologias inseridas neste trabalho foi considerado como custo para a soja transgênica, pois ficou evidenciado que a soja convencional aferiu um sobrepreço de 5\%. Como neste estudo o preço considerado da soja comercial foi de $\mathrm{R} \$ 30,00 /$ saco de $60 \mathrm{~kg}$, então esse sobrepreço de 5\% representa a quantia de $\mathrm{R} \$ 1,50 /$ saco. A produtividade estimada foi de 50 sacos de $60 \mathrm{~kg} \cdot \mathrm{ha}^{-1}$ ou 3 mil kg.ha ${ }^{-1}$. Dessa forma, multiplicando-se os 50 sacos pelo valor de $\mathrm{R} \$ 1,50 /$ saco, chega-se a um valor total de $\mathrm{R} \$ 75,00 /$ ha, considerado como custo para a soja transgênica.

Da mesma forma, o diferencial de produtividade entre a soja transgênica e a soja convencional foi considerado como custo para aquela tecnologia que aferiu o menor valor.

No estudo, assumiu-se para a soja transgênica uma produtividade $3,1 \%$ menor que a convencional, recebendo o diferencial como custo. Como a produtividade estimada foi de $3 \mathrm{mil} \mathrm{kg} \cdot \mathrm{ha}^{-1}$, então, $3,1 \%$ sobre esse valor fornece a quantia de $90 \mathrm{~kg}$ ou 1,5 sacos/ha. 0 preço do saco de $60 \mathrm{~kg}$ considerado foi de $\mathrm{R} \$ 30,00$, portanto, multiplicando-se 1,5 sacos por $R \$ 30,00$ resulta em $R \$ 45,00 /$ ha de custo para a soja transgênica.

A segregação interna, que consiste nos trabalhos diferenciados de recepção, secagem e armazenamento, foi incluída no custo da soja convencional, pois é ela que está sendo diferenciada para mercados específicos. Quanto menor o volume de um produto diferenciado, mais difícil e onerosa é sua separação e manipulação. Essa segregação visa à total separação desses grãos para não contaminar os grãos da soja convencional.

Um dos gerentes agrícolas entrevistadosinformou que para a realização da segregação interna da soja transgênica deve-se considerar um custo adicional de $\mathrm{R} \$$ 6,90/ton (baseado em um câmbio de R\$ 2,30 para cada US\$ 1,00$)$. Considerando ainda uma produtividade de 3 mil kg.ha-1 de soja transgênica, resulta em um custo de $\mathrm{R} \$ 20,70 /$ ha.

Ainda em relação ao custo de segregação interna, o outro gerente agrícola informou que, com 10\% de produção com soja transgênica, prefere-se construir uma nova unidade de recepção para evitar misturas de grãos com a soja convencional. Nesse caso o custo seria de $\mathrm{R} \$ 7,25 /$ ton. Da mesma forma, considerando uma produtividade de 3 mil kg.ha- ${ }^{-1}$ chega-se a um custo de $R$ \$21,75/ha. Para este estudo, foi considerado o menor valor de segregação interna ( $R$ \$ 20,70/ha).

Em relação aos herbicidas utilizados na soja convencional, chegou-se a valores médios em litros/ha em função do volume consumido por unidade de área. Na Tabela 5, pode-se observar os três herbicidas mais consumidos na soja convencional pelos produtores de uma cooperativa da região de Castro - PR. Para o estabelecimento dos custos, foram utilizados os preços unitários de cada herbicida através de lista fornecida pelo gerente da cooperativa entrevistado. Para o herbicida glifosato, adotou-se uma dose média parcelada em duas vezes numa forma sequencial $\left(1,50\right.$ l.ha ${ }^{-1}+1,00$ l.ha $\left.{ }^{-1}\right)$ totalizando 2,50 l.ha ${ }^{-1}$. Essa forma sequencial de aplicação foi adotada para o glifosato para uniformizar os parâmetros de avaliação, já que na soja convencional é usual a aplicação dos herbicidas em duas vezes. A dose de 2,50 1.ha ${ }^{-1}$ de glifosato aplicada na forma parcelada é indicada pela multinacional fabricante do glifosato quando existe uma infestação média de ervas daninhas. Como o glifosato registrado para a soja transgênica ainda não está sendo comercializado no Paraná, considerou-se o preço do glifosato comum. $\mathrm{Na}$ primeira aplicação de herbicida pós-emergente na soja convencional, usa-se uma mistura de dois herbicidas para combater ervas daninhas com folhas largas e na segunda, utiliza-se um outro herbicida para eliminar ervas de folhas estreitas. Para os herbicidas da soja convencional, existe necessidade da adição de um óleo mineral para melhorar a ação desses produtos nas ervas daninhas; portanto 0 valor desse adjuvante deve ser considerado no custo da soja convencional. 
Tabela 5. Herbicidas utilizados em pós-emergência na soja convencional e na transgênica com as respectivas doses e preços.

\begin{tabular}{|c|c|c|c|c|c|}
\hline $\begin{array}{c}\text { Herbicidas } \\
\text { (nomes técnicos) }\end{array}$ & $\begin{array}{l}\text { Volume } \\
\text { comercializado } \\
\text { (1 ou kg) }\end{array}$ & $\begin{array}{c}\text { Área } \\
\text { aplicada (ha) }\end{array}$ & $\begin{array}{c}\text { Dose média } \\
\left(1 \text { ou } \mathrm{kg} \mathrm{ha}^{-1}\right) \\
\text { do produto } \\
\text { comercial }\end{array}$ & $\begin{array}{c}\text { Preço } \\
\text { (R\$/l ou kg) }\end{array}$ & $\begin{array}{l}\text { Custo/ha } \\
\text { (R\$/ha) }\end{array}$ \\
\hline Lactofen & 10.6171 & $29.280,07$ & 0,361 & 59,06 & 21,26 \\
\hline Cloransulan - metil & $1.350,72 \mathrm{~kg}$ & $38.029,18$ & $0,035 \mathrm{~kg}$ & 1496,49 & 52,38 \\
\hline Tepraloxidim & 19.5661 & $24.500,00$ & 0,81 & 84,92 & 67,94 \\
\hline $\begin{array}{l}\text { Adjuvante para herbicidas } \\
\text { da soja convencional }\end{array}$ & - & - & 1,0 & 6.34 & 6.34 \\
\hline $\begin{array}{l}\text { Glifosato pós-emergente } \\
\text { para soja transgênica }\end{array}$ & - & - & 2,51 & 9,00 & 22,50 \\
\hline
\end{tabular}

Fonte: dados da pesquisa.

Tabela 6. Diferenças de custos entre a soja transgênica e a soja convencional em função das variáveis consideradas (R $\$ /$ ha).

\begin{tabular}{lccc}
\hline & Soja convencional (A) & Soja transgênica (B) & Diferença (A) - (B) \\
\hline Herbicidas pós-emergentes & 147,91 & 22,50 & 125,41 \\
Sementes & 49,50 & 110,00 & $-60,50$ \\
Taxa tecnológica & 0,00 & 16,50 & $-16,50$ \\
Segregação interna & 20,70 & 0,00 & 20,70 \\
Sobrepreço do grão & 0,00 & 75,00 & $-75,00$ \\
Produtividade & 0,00 & 45,00 & $-45,00$ \\
Custos de máquinas com mão de obra & 367,23 & 367,23 & 0,00 \\
Fertilizantes, inseticidas, fungicidas, adjuvantes & 442,28 & 442,28 & 0,00 \\
e herbicidas para dessecação em pré-emergência & 28,79 & 27,89 & 0,90 \\
Juros sobre insumos e capital próprio & 99,38 & 99,38 & 0,00 \\
Recepção, secagem e taxas & 45,70 & 45,70 & 0,00 \\
Mão de obra fixa e temporária & 124,65 & 124,65 & 0,00 \\
Custos de administração & 107,92 & 107,92 & 0,00 \\
Remuneração da terra & 1434,06 & 1484,05 & $-49,99$ \\
Custo total & & & \\
\hline
\end{tabular}

Fonte: dados da pesquisa.

Na Tabela 6, são mostradas as diferenças de custos usando-se as variáveis aqui discutidas: preços de sementes, a taxa tecnológica, herbicidas, produtividade, preços diferenciados de mercado da soja convencional em relação à transgênica, segregação interna, custos de máquinas com mão de obra, fertilizantes, inseticidas, fungicidas, adjuvantes, herbicidas para dessecação em pré-emergência, juros sobre insumos e capital próprio, recepção e secagem, taxas, mão de obra fixa e temporária, custos de administração e remuneração da terra.

Observa-se pela Tabela 6 que existem diferenças de custo/ha entre as duas tecnologias levando-se em conta as variáveis consideradas neste estudo. Utilizando todas essas variáveis, a soja transgênica torna-se mais onerosa que a convencional em $\mathrm{R} \$ 49,99 /$ ha.
Uma diferença marcante observada na Tabela 6 é o custo da semente da soja transgênica, em relação à convencional, somando-se o preço da semente mais a taxa tecnológica cobrada pela multinacional para uso do gene, chega-se a um valor de $R \$ 126,50 /$ ha contra $R \$ 49,50 /$ ha da semente da soja convencional. A diferença observada de $\mathrm{R} \$ 77,00 /$ ha é superior ao apresentado pela Comissão Europeia (2003), que foi de $€ 15,00 /$ ha.Com a análise dos custos de produção em função da inclusão ou não das variáveis taxa tecnológica, produtividade e sobrepreço da soja convencional, possibilitou uma reflexão dos vários argumentos comentados neste trabalho. Em seguida, na Tabela 7 são discutidos diversos cenários possíveis na relação custos soja transgênica - soja convencional. Nessa Tabela 7, os custos complementares foram denominados de outros custos. Para maiores detalhes sobre esses outros custos, estes estão explicitados na Tabela 6. 
Portanto, em função da inclusão ou não das variáveis pode-se criar seis cenários:

- Cenário A: mesma produtividade e sem ocorrência de sobrepreço para a soja convencional, incluindo-se apenas a variável taxa tecnológica, (soja transgênica A, conforme Tabela 7). Nessa situação, o custo para a soja convencional é de $R \$ 1434,06 /$ ha e para a transgênica fica em R\$ 1364,05/ha. Nota-se, então, uma diferença de $\mathrm{R} \$ 79,01 / \mathrm{ha}$, sendo nesse caso a soja convencional mais onerosa que a transgênica.

- Cenário B: mesma produtividade, sem ocorrência de sobrepreço para a soja convencional e sem cobrança de taxa tecnológica (soja transgênica B, conforme Tabela 7). Nesse cenário, o custo da soja transgênica fica $\mathrm{R}$ \$ 86,51 menor.

- Cenário C: mesma produtividade, com taxa tecnológica e sem o sobrepreço para a soja convencional (soja transgênica C, conforme Tabela 7). 0 custo de produção da soja transgênica nessa situação é de $R \$ 25,01 /$ ha.

- Cenário D: mesma produtividade para os dois tipos de soja, porém mantendo-se os custos de sobrepreço e taxa tecnológica (soja transgênica D, conforme Tabela 7). Constata-se nessa situação que o custo da soja transgênica é de $R$ \$ 4,99/ha.

- Cenário E: considera o diferencial de produtividade entre os dois tipos de soja, o sobrepreço e a taxa tecnológica (soja transgênica E). Em relação a esse cenário, a diferença constatada indica que a soja transgênica fica mais cara em R\$ 49,99/ha em relação à convencional.

- Cenário F: considera a mesma produtividade, o sobrepreço da soja convencional e sem a taxa tecnológica (soja transgênica F). Nesse último cenário, a soja transgênica fica mais cara em R\$ 33,49/ha. Em função desses resultados comparativos apresentados, pode-se equacionar a diferença de custo entre as duas tecnologias consideradas, a soja transgênica e a soja convencional, da seguinte forma: (Equação 1)

$\operatorname{Custo}_{(C-T)}=\left(H_{c}-H_{t}\right)+S_{h}\left(S_{c}-S_{t}\right)+\left(S E G \times P R_{c}\right)-$

$\left(S_{h} \times T_{t}\right)-\left(P R_{c} \times P_{s}\right) \times \frac{S_{p}}{100}-\left(\frac{P R_{c} \times D_{p}}{100 \times P_{s}}\right)+\left(O_{c}-O_{t}\right)$

onde:

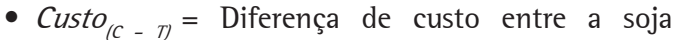
convencional e a transgênica ( $\mathrm{R} \$ / \mathrm{ha}$ )

- $H_{c}=$ custo dos herbicidas da soja convencional;

- $H_{t}=$ custo do herbicida para a soja transgênica;

- $S_{\mathrm{h}}=$ quantidade de semente usada por hectare, em quilos (kg.ha-1);

- $S_{c}=$ custo do quilo da semente da soja convencional;

- $S_{t}=$ custo do quilo da semente da soja transgênica;

- $T_{t}=$ taxa tecnológica da soja transgênica $(\mathrm{R} \$ / \mathrm{kg})$;

- $P_{s}=$ preço de mercado do saco de $60 \mathrm{~kg}$ de soja grão;

- $S_{p}=$ sobrepreço praticado para a soja convencional certificada (\%);

- $P R_{c}=$ produtividade da soja convencional em sacos de $60 \mathrm{~kg} \cdot \mathrm{ha}^{-1}$;

- $D_{p}=$ diferença de produtividade da soja transgênica em relação à convencional (\%);

- $S E G$ = custo de segregação interna para a soja convencional $(\mathrm{R} \$ / \mathrm{kg})$;

- $P R_{c}=$ produtividade da soja convencional em kg.ha-1;

- $O_{c}=$ outros custos da soja convencional; e

- $O_{t}=$ outros custos da soja transgênica.

Assumindo um cenário no qual, a médio prazo, os fatores custo dos herbicidas, sementes e outros custos são fixos ou pouco variáveis e assumindo

Tabela 7. Custos comparativos entre soja transgênica e soja convencional em função da inclusão ou não das variáveis do estudo (R\$/ha).

\begin{tabular}{|c|c|c|c|c|c|c|c|}
\hline & \multirow{2}{*}{ Soja convencional } & \multicolumn{6}{|c|}{ Soja transgênica } \\
\hline & & (A) & (B) & (C) & (D) & (E) & (F) \\
\hline Herbicidas & 147,91 & 22,50 & 22,50 & 22,50 & 22,50 & 22,50 & 22,50 \\
\hline Sementes & 49,50 & 110,00 & 110,00 & 110,00 & 110,00 & 110,00 & 110,00 \\
\hline Taxa tecnológica & 0,00 & 16,50 & 0,00 & 16,50 & 16,50 & 16,50 & 0,00 \\
\hline $\begin{array}{l}\text { Segregação } \\
\text { interna }\end{array}$ & 20,70 & 0,00 & 0,00 & 0,00 & 0,00 & 0,00 & 0,00 \\
\hline Sobrepreço & 0,00 & 0,00 & 0,00 & 0,00 & 75,00 & 75,00 & 75,00 \\
\hline Produtividade & 0,00 & 0,00 & 0,00 & 45,00 & 0,00 & 45,00 & 45,00 \\
\hline Outros custos & 1215,95 & 1215,05 & 1215,05 & 1215,05 & 1215,05 & 1215,05 & 1215,05 \\
\hline Custo total & 1434,06 & 1364,05 & 1347,55 & 1409,05 & 1439,05 & 1484,05 & 1467,55 \\
\hline $\begin{array}{l}\text { Diferença } \\
\text { (conv.- transg.) }\end{array}$ & & 70,01 & 86,51 & 25,01 & $-4,99$ & $-49,99$ & $-33,49$ \\
\hline
\end{tabular}

Fonte: dados da pesquisa. 
produtividades iguais para os dois tipos de soja, a Equação (1) fica:

$$
\begin{aligned}
& \text { Custo }_{(C-T)}=(147,91-22,50)+55(0,90-2,00)+ \\
& \left(S E G \times P R_{c}\right)-55 T_{t}-\left(P R_{c} \times P_{s}\right) \times \frac{S_{p}}{100}-0-0+
\end{aligned}
$$

$(1215,95-1215,05)$

Ainda:

$$
\begin{aligned}
& \operatorname{Custo}_{(C-T)}=125,41-60,5+20,70-55 T_{t}- \\
& \left(P R_{c} \times P_{s}\right) \times \frac{S_{p}}{100}+0,90
\end{aligned}
$$

$$
\operatorname{Custo}_{(C-T)}=86,51-55 T_{t}-\left(P R_{c} \times P_{s}\right) \times \frac{S_{p}}{100}
$$

Considerando-se a produtividade da soja convencional em uma média de 3 mil kg.ha- ${ }^{-1}$ (50 sacos de $60 \mathrm{~kg} \cdot \mathrm{ha}^{-1}$ ) e o preço do saco de $60 \mathrm{~kg}$ de $R \$ 30,00$, chega-se ao seguinte:

$$
\begin{aligned}
& \operatorname{Custo}_{(C-T)}=86,51-55 T_{t}-(50 \times 30,00) \times \frac{S_{p}}{100} \\
& \operatorname{Custo}_{(C-T)}=86,51-\left(55 T_{t}+15,00 \times S_{p}\right)
\end{aligned}
$$

Logo, quando o termo $\left(55 T_{t}+15,00 S_{p}\right)$ for maior que 86,51, o custo da soja transgênica fica acima do custo da soja convencional. Esse termo é função da taxa tecnológica determinada pela empresa detentora do gene e do sobrepreço pago pelo mercado para a soja convencional.

Essa equação permite determinar valores da taxa tecnológica da soja transgênica em função dos sobrepreços para a soja convencional certificada, igualando dessa forma os custos de produção dos dois tipos de soja.

Ou seja, usando-se o valor 5 para $S_{p}$ obtém-se:

$$
\begin{aligned}
& \text { Custo }_{(C-T)}=86,51-\left(55 T_{t}+15,00 * 5\right) ; \\
& \text { Custo }_{(C-T)}=86,51-\left(55 T_{t}+75,00\right) ; \mathrm{e} \\
& \text { Custo }_{(C-T)}=86,51-(55 \times 0,21+75,00) .
\end{aligned}
$$

Dessa forma, para um sobrepreço de 5\% para a soja convencional certificada e um valor pago de $\mathrm{R} \$ 30,00$ por saco de $60 \mathrm{~kg}$, o valor da taxa tecnológica da soja transgênica deve se situar próximo de $\mathrm{R} \$ 0,21 / \mathrm{kg}$ de sementes, para ter um custo equivalente ao da soja convencional. Qualquer valor acima de $\mathrm{R} \$ 0,21 / \mathrm{kg}$ estipulado para a taxa tecnológica torna a soja transgênica mais onerosa.

\section{Conclusões}

Os resultados apresentados neste artigo foram obtidos na fase de introdução da soja transgênica no Paraná e também em uma região específica de atuação de duas cooperativas paranaenses, portanto num período de tempo determinado. Como a tecnologia "soja transgênica" ainda é nova no Brasil, poderão ocorrer em outras regiões com características próprias de tecnologia, preços e meio ambiente, resultados diferentes dos obtidos nesta pesquisa. No entanto, os resultados iniciais de produtividade comparativos entre a soja transgênica e a convencional obtidos nesta pesquisa foram de uma região ampla do Estado do Paraná e indicam uma tendência positiva para a soja convencional. Ressalta-se que as variedades transgênicas foram comparadas com as respectivas variedades convencionais recorrentes comerciais.

Neste estudo, evidenciou-se pelo cálculo do custo de produção comparativo entre a soja transgênica e a convencional que, quando não se consideram as variáveis produtividade comparativa e preços diferenciados dos grãos, a soja transgênica apresenta-se bastante competitiva, com $R \$ 70,01 /$ ha a menos de custo que a soja convencional. Mesmo com a redução significativa de custo pelo menor uso de herbicidas na soja transgênica, esse fato é minimizado pelo maior preço atual cobrado pela semente da variedade de soja transgênica e pela taxa tecnológica utilizada. Por outro lado, quando se consideram as variáveis produtividade comparativa e preço diferenciado da soja convencional, a soja transgênica fica mais onerosa em $\mathrm{R}$ \$49,99/ha.

Pela equação determinada neste trabalho, verificou-se que, para valores de sobrepreços acima de 5\% para a soja convencional, o valor da taxa tecnológica das sementes de soja transgênica não deve exceder a $R \$ 0,21 / \mathrm{kg}$ de sementes. Para essa situação, valores de taxa tecnológica acima de $\mathrm{R} \$ 0,21 / \mathrm{kg}$ de sementes torna a soja transgênica mais onerosa. Essa consideração é válida quando não são consideradas as diferenças de produtividade entre as duas tecnologias.

Pode-se concluir, em relação aos custos comparativos de produção entre a soja transgênica e a convencional, que os argumentos que afirmam sobre o menor custo com a introdução da soja transgênica não são corretos, pelo menos a curto prazo. Para a realização de afirmações sobre custo de produção comparativo entre tecnologias, deve-se estabelecer quais variáveis e fontes estão sendo utilizadas. Informações genéricas sobre o assunto podem deturpar os resultados confundindo os produtores e decisores do agronegócio. Por 
outro lado, com os custos comparativos levantados, pode-se auxiliar a sociedade produtora e os decisores gerenciais no discernimento de questões relacionadas, indicando de forma confiável a viabilidade e os benefícios dessa nova tecnologia transgênica. Dessa forma, terão oportunidade de decidir e direcionar ações para segmentação de produtos.

Portanto, a decisão de uso da soja transgênica deve passar por uma análise mais aguçada incluindo todas as variáveis que interferem nos resultados. Além disso, uma análise de mercado para a soja convencional segregada e certificada deve ser observada, já que por este estudo foi identificado que já existe um direcionamento de parte da produção dessa soja convencional das cooperativas entrevistadas para o mercado externo com um sobrepreço de 5\%. Esse volume de soja convencional certificada e comercializada pelas cooperativas caracteriza um nicho de mercado que poderá se estabelecer com mais consistência nos próximos anos. Conforme a adesão pela soja transgênica for se concretizando, outros nichos para a soja convencional poderão surgir.

A possibilidade de ocorrer nos próximos anos um aumento da produção da soja transgênica com características diferenciadas de qualidade levará o setor produtivo a adotar segregações nos armazéns impondo, dessa forma, um custo adicional que deverá ser pago pelo mercado comprador.

Ressalta-se aqui também a dúvida em relação à competitividade das variedades transgênicas nessa fase inicial, tanto pela diferença de produtividade mencionada como também pelos custos das sementes incluindo-se a taxa tecnológica. Espera-se que, num prazo pouco distante, através de técnicas de melhoramento vegetal utilizando a biotecnologia, as variedades transgênicas lançadas no mercado sejam tão produtivas quanto as convencionais. Da mesma forma, com o aumento do volume de sementes transgênicas existirá uma tendência de diminuição dos preços praticados para essas sementes. Nessa situação, os prêmios para os preços da soja convencional devem ser convidativos, caso contrário, pela praticidade de uso o produtor poderá optar pela transgênica.

Certificou-se, através das entrevistas com os gerentes agrícolas das cooperativas, no que tange ao tema custo de segregação interna, uma dificuldade desses entrevistados para visualizar um cenário com a participação da soja transgênica com um volume de 10\% no mercado. Com a tendência de se gerarem, seja através da soja convencional ou da transgênica, produtos segregados para atender nichos de mercado específicos, as decisões de investimentos em silos adjacentes nas unidades receptoras existentes ou construção de unidades próprias separadas devem ser criteriosamente analisadas e, com certeza, essas dúvidas passarão na pauta de discussões dos administradores e decisores do agronegócio. Pelo cenário apresentado até o momento, esperam-se mudanças significativas nos processos produtivos e relacionamentos nas cadeias agroindustriais. 0 sistema de logística na agricultura passará por acertos durante a introdução da soja transgênica e esse comportamento poderá ser uma preocupação constante conforme novos produtos vão sendo lançados no mercado.

Deduz-se que, em função dos resultados obtidos neste trabalho, existirá uma tendência de utilização da soja transgênica no Paraná num ritmo lento e mais organizado, diferente do ocorrido no Rio Grande do Sul. As sementes da soja transgênica possuem um maior custo e as variedades de soja transgênicas atuais disponíveis apresentam menor produtividade. Dessa forma, a decisão pelo seu uso poderá ocorrer de uma forma paulatina e reservada, em princípio, para áreas com problemas de ervas daninhas com resistência aos herbicidas convencionais.

Entende-se que a estratégia adotada pelo Estado do Paraná em tentar proibir o uso da soja transgênica pelos produtores desse estado possui um fundamento de mercado, isto é, valorizar um produto regional certificado destinado para um nicho externo de mercado. No entanto, essa atitude torna-se difícil de ser amparada quando se trata de uma tecnologia de impacto como a soja transgênica.

Nesse sentido, pode-se afirmar que o crescimento da área plantada com soja transgênica cresceu no mundo e também no Paraná. Pelas informações das produtoras de sementes, atualmente a soja transgênica ocupa 50\% da área plantada no Estado do Paraná. Na região do nosso estudo, CamposGerais - PR, as duas cooperativas estão utilizando ainda em média 15\% da área com soja transgênica. Os motivos por ainda estarem num patamar baixo de uso são os resultados de baixa produtividade da soja transgênica e o sobrepreço conseguido pela soja convencional na exportação. No entanto, sabe-se que atualmente, pelos resultados principalmente nos EUA com a introdução de novas variedades e eventos de transgenia na soja (também no Brasil, mas de forma pontual), consegue-se maior produtividade que a soja convencional. Salienta-se ainda que os resultados apresentados neste artigo foram obtidos na fase de introdução da soja transgênica no Paraná e também numa região específica de atuação de duas cooperativas paranaenses, portanto num 
período de tempo determinado. Apesar da evolução da área plantada com soja transgênica no mundo, os resultados apresentados na pesquisa ainda refletem a situação atual específica da região do estudo, isto é, introdução mais lenta da soja transgênica, segregação da soja convencional para obtenção do sobrepreço e menores produtividades em média da soja transgênica em relação à convencional.

Portanto, a soja transgênica, pela sua praticidade de uso, perspectiva de menor custo e euforia de consumo gerada por uma tecnologia de ponta, convida os produtores para o seu uso. $\mathrm{E}$, pela velocidade de adoção da soja transgênica em outros países, percebe-se que essa tendência é inexorável. Fica evidente neste trabalho, porém, que a tecnologia "soja transgênica" no período e região do estudo foi considerada polêmica e utilizada com cautela.

\section{Referências}

BIANCHI, M. A. Manejo de plantas daninhas em soja RR: a experiência do Rio Grande do Sul. Paraná: FUNDACEP, 2005.

CARVALHO, M. A. Comércio agrícola e vulnerabilidade externa brasileira. Agricultura, v. 49, n. 2, p. 55-69, 2002.

CHADDAD, F. R.; NEVES, M. F.; LAZZARINI, S. G. Gestão de negócios em alimentos. São Paulo: Editora Pioneira Thompson Learning, 2002. $130 \mathrm{p}$.

Comissão Européia. Designações de produtos registrados. Disponivel em: <www.europa.eu.int/comm/agriculture/ qual/pt/prod_pt.htm>. Acesso em: Novembro 2003.

EMBRAPA SOJA. Formulários para inscrição de cultivares no Registro Nacional de Cultivares - MAPA. Londrina: EMBRAPA, 2005. 10 p.
GIORDANO, S. R. Competitividade regional e globalização. São Paulo, 1999. 226 p. Tese (Doutorado em Geografia) - Universidade de São Paulo - USP. Instituto Brasileiro de Geografia e Estatística - IBGE. Disponível em: <http://www.ibge.gov.br/home/estatistica/indicadores/ agropecuaria/lspa/default.shtm>. Acesso em: Maio 2005.

KOTLER, P. Marketing. São Paulo: Editora Atlas, 1989. 595 p.

MARGARIDO, M. A.; FERNANDES, J. M.; TUROLLA, F. A. Análise da formação de preço no mercado internacional de soja: o caso do Brasil. Agricultura, v. 47, n. 2, p. 71-85, 2002.

MARQUES, P. V.; AGUIAR, D. R. D. Comercialização de produtos agrícolas. São Paulo: USP, 1993. 295 p.

MORAIS, R. J. Segurança e Rotulagem de Alimentos Geneticamente Modificados - SERAGEM. Rio de Janeiro: Forense, 2004. p. 15-48.

PELAEZ, V. Soja transgênica consome 30\% mais herbicida a partir do terceiro ano de plantio. Disponível em: <www. celepar8cta.pr.gov.br/sécs/cnoti.nsf/nd>. Acesso em: Novembro 2004.

PORTER, M. Estratégia competitiva: técnicas para análise de indústrias e da concorrência. Rio de Janeiro: Editora Eselvier, 1986. 362 p.

SILVEIRA, J. V. F. Estratégia de segmentação de mercado no agronegócio: o caso da inserção da soja transgênica no estado do Paraná. Ponta Grossa, 2005. 141 p. Dissertação (Mestrado em Engenharia de Produção) - Universidade Tecnológica Federal do Paraná - UTFPR.

SILVEIRA, J. V. F.; RESENDE, L. M.; LEITE, M. L. G. Vantagem competitiva no setor agroindustrial: o caso dos transgênicos. In: VI SIMPÓSIO DE ADMINISTRAÇÃO DA PRODUÇÃO, LOGÍSTICA E OPERAÇÕES INTERNACIONAIS - SIMPOI, 2003. Anais...

WILKINSON, J. Estudo da competitividade de cadeias integradas no Brasil: impactos das zonas de livre comércio. Campinas: UNICAMP, 2002. 97 p.

\title{
Market strategies in the Paraná state agribusiness: conventional soybean vs. transgenic soybean
}

\begin{abstract}
The objective of this work was to determine the comparative factors of the production costs between conventional and transgenic soybean, with a view to informing strategies for decision making among agribusiness actors, analyzing the Paraná state (Brazil) reality. The argument that the introduction of the transgenic soybean equals lower costs, proved to be incorrect. This study demonstrated that despite the practicality in the technology of the transgenic soybean, there are also arguments supported by data that raise questions regarding the use of this technology, in particular regarding the economic and the technical aspects. Even with the significant reduction in costs due to the lower use of herbicides with the transgenic soybean, this fact is minimized by the higher price charged for the transgenic variety of seed, by the high technological tax used and by the lower productivity offered by the varieties of transgenic soybean on the market compared to conventional soybean varieties.
\end{abstract}

\section{Keywords}

Transgenic soybean. Market strategies. Comparative production costs. 